\title{
EL PROBLEMA DE LOS ORIGENES DE LOS ESTADOS HISPANOAMERICANOS EN LA HISTORIOGRAFIA RECIENTE Y EL CASO DEL RIO DE LA PLATA
}

José Carlos Chiaramonte

(Instituto de Historia Argentina y Americana Dr. Emilio Ravignani, Facultad de Filosofía y Letras, Universidad de Buenos Aires/Argentina)

Según un punto de vista generalizado en la historigrafía latinoamericana, los proyectos de nuevos estados nacionales que se difundieron con la Independencia implicaban la previa existencia de nacionalidades; esto es, de comunidades conscientes de poseer una identidad nacional. Como habremos de comprobar, se trata de un punto de vista que en el caso rioplatense nos parece manifiestamente falso y que tampouco juzgamos válido para el conjunto de Hispanoamericano, punto de vista que impide además percibir el desconcierto que al respecto se manifestaba hacia 1810 .

Lo erróneo de tal punto de vista pudo pasar inadvertido por efecto de algunos de los presupuestos con que suele abordase la formación del Estado nacional en América Latina. El núcleo de la dificultad, permítasenos reiterarlo, está en que comúnmente se tiende a asociar la afirmación política de una comunidad nacional, expresada en la emergencia de ese Estado, a algo que no resulta tan cierto: la previa existencia de una definida nacionalidad, de la cual ese Estado sería derivación necessaria. El conjunto, entonces, de una comunidad 
con distintiva fisionomia nacional, y de una aspiración a añadir a esa comunidad una presencia política independiente en el ámbito internacional, sería un supuesto generalizado en los estudios sobre la formación de las naciones latinoamericanas. Supuesto fundado, a su vez, en otro, relativo a la história europea: que tal habría sido el caso de la emergencia de las naciones europeas. Sin embargo, estos supuestos no por más difundidos resultan menos dudosos a la luz de los avances de la historiografía reciente.

Como ha sido observado para el caso de la formación de naciones europeas durante el siglo XIX, esos elementos no han estado necesariamente vinculados a lo largo de la historia moderna, de manera que no sería lícito confundir el sentimiento de identidad cultural o étnico - generalmente regional -, que existe en Europa desde la Edad Media, o aún antes, con el sentimiento nacional que acompaña la emergencia de unidades políticas estatales de nuevo tipo. ${ }^{1}$

Pero, más allá de la discusión sobre su validez general, la secuencia nacionalidad-estado nacional-nación no nos parece que refleje el caso de los paises que surgen del colapso de la dominación hispana. En cambio, juzgamos que tal perspectiva es fruto de la voluntad nacionalizadora de la primera historiografía nacional del siglo pasado que marcó profundamente una huella por la que siguío hasta ahora la mayor parte de la historiografía latinoamericanista. El afán por afirmar los débiles estados surgidos del derrumbe ibérico, fomentando la conciencia de una nacionalidad distinta, propósito explícito en esa historiografía, ${ }^{2}$ facilitó la generalizada suposición de que la Independencia fué fruto de la necesidad de autonomía de nacionalidades ya formadas.

\section{LOS PRESUPUESTOS HISTORIOGRÁFICOS DEL PROBLEMA}

Lo español americano y las tres formas de identidad política rioplatense hacia la Independencia.

Es así que en el caso del Río de la Plata, y probablemente en el de otras regiones del mundo hispanoamericano, la casi exclusiva 
preocupación por rastrear la génesis del sentimiento nacional tendió a ocultar la real natureleza de la indefinición en que se encontraba el sentimiento colectivo en los días siguientes a la Indepedencia. Nos referimos al equívoco corriente que consiste en enfocar las manifestaciones de diferencia u oposición de los americanos con respecto a los europeus desde la perspectiva marcada por el problema de la identidad nacional posterior a la independencia, de manera que resultam convertidas en rasgos nacionalistas. Porque los fenómenos de diferenciación y relativa autoidentificación de los pueblos iberoamericanos son una cosa, y el fenómeno de la identidad nacional, otra. ${ }^{3}$

Estos supuestos que la voluntad nacionalizadora de la historiografía del siglo pasado legó a la actual, impiden una adecuada comprensión de las formas que asumía la identidad colectiva de la ambígua coexistencia, por momentos, de formas diversas y aún antagónicas.

"Estas tres tendencias hacia la conformación de una identidad política no han sido ignoradas en la historiografía del período. La hispanoamericana, prolongación del sentimiento de espanol americano elaborado durante el período colonial, la provincial, asentada en el sentimiento lugareño, y la rioplatense - luego Argentina -, de más compleja delimitación, han sido motivo de interés, por diversas razones, para la historiografía del siglo XIX. Sin embargo, poco se ha atendido a que el hecho mismo de su coexistencia, a la vez que reflejaba la ambigüedad en que se encontraba el sentimiento colectivo inmediatamente despúes de producida la Independencia, traducia también en el curso de las variaciones de su importancia relativa, la dirección que seguía el processo de elaboración de una identidad política dentro del crítico proceso de formación de los nuevos países independientes."4 


\section{El supuesto modelo europeo de formación de naciones, y el tema de la identidad.}

Lo que sucede, hemos señalado más ariba, es que la cuestión que nos ocupa padece también el inadvertido encierro en el supuesto modelo europeo de formación de las naciones modernas. Esto es, en el supuesto de que las naciones modernas han sido fruto natural de una larga formación de la identidad nacional. ${ }^{5}$ Aún en recientes enfoques interdisciplinarios respecto del fenomeno de la identidad, puede entreverse un criterio que tiende irresistiblemente a considerar como un continuo histórico el proceso que va de las identidades étnicas más elementales a la nación moderna. De manera que ésta no sería así más que un caso particular, el último momento, de una línea evolutiva cuyo punto de partida estaría representada por una unidad social con un mínimo de rasgos capaces de fundar una posible identidad. ${ }^{6}$

Este criterio, de alguna manera, fusiona dos problemas distintos que supone ser uno solo, el de las identidades étnicas y el de la génesis de la nación. Por otra parte, tiende a considerar la etnicidad como algo dado, esto es, algo que, metodológicamente, asume la función de lo natural, frente a las construcciones de la Historia. ${ }^{7} \mathrm{La}$ cuestión es para nosotros capital porque aquel criterio constituye el trasfondo del punto de vista difundido en la historiografía latinoamericana, que los hemos ya señalado y que comprobaremos en trabajos como los que consideramos más adelante: el punto de vista según el cual las naciones iberoamericanos surgen como producto de la formación, durante el período colonial, de una correspondiente identidad cultural.

Desde otro punto de partida, la perspectiva distinta, según la cual el hecho nacional y la identidad cultural resultan dos fenómenos de diversa naturaleza, no necesariamente vinculados, y sólo confluyentes historicamente durante el siglo XIX, también ha sido puesta de relieve en un balance historiográfico europeo:

"Es también evidente que el Estado-nación es una unidad impropia para muchos períodos del pasado, quizá para la mayoría, y que al hablar, por ejemplo, 
de la historia de Francia, en una época en la que de hecho separaban grandes diferencias al Languedoc, Bretaña, Lorena y Gascuña, estamos imponiendo un modelo anacrónico y una interpretación teleológica."

Si se observa bien el párrafo citado, se percibirá cómo el autor advierte, por una parte, la no correspondencia de espacio nacional y espacios que reflejan una identidad cultural. Y, por otra, cómo alerta, a nuestro juicio atinadamente, sobre el riesgo de incurrir en el anacronismo de desfigurar la historia de esas regiones imponiéndole el molde historiográfico de la futura nación.

\section{La confusión de espíritu americano y sentimiento nacional.}

La fuerte influencia que la primera historiografía nacional de los países latinoamericanos ejerció desde mediados del siglo pasado sobre la cuestión del origen de las nacionalidades, moldeó de tal manera el enfoque de la cuestión, que hoy ese enfoque no sólo impera entre los historiadores latinoamericanos sino que se ha extendido a la historiografía latinoamericanista europea y norteamericana. El núcleo de esa influencia es el postulado de la existencia de una nacionalidad en cada uno de los futuros países hispanoamericanos en el momento de la Independencia. Y su expresión más frecuente es la de leer cada alarde de sentimiento criollo - esto es, espanol americano -, como una manifestación nacionalista. Es decir, no de un nacionalismo americano, sino de un nacionalismo mexicano, colombiano, argentino, u otro, según sean los casos. En suma, convertir las expresiones de identidad criolla en manifestaciones de nacionalismos locales.

Conviene que nos detengamos en este fenómeno de lectura equívoca, selecionando dos o tres ejemplos nítidos, porque estimamos que se trata de un riesgo en el que hemos incurrrido más de lo que solemos advertir, y cuyas dimensiones deformantes sobre el análisis histórico son de extrema importancia. Uno de estos ejemplos lo podemos encontrar en la obra de un historiador argentino, publicada en 1952, en la que expresa mención de América por Bernardino Rivadavia es leída como equivalente de Argentina o Río de la Plata. 
Se trata de una carta de Rivadavia a Puyerredón, de marzo de 1817, cuyos comentarios elogiosos a las previsiones del Abate de Pradt sobre la inevitable independencia de América, son interpretadas por el autor como afirmaciones de la "madurez nacional para la emancipación", expresión en la que nacional refiere a Buenos Aires o al Río de la Plata. El abate de Pradt, escribía Rivadavia,

"...con el fin de forzar el convencimiento de la independencia de América, no ha omitido hasta los argumentos mismos que nos rebajan."9

Este párrafo donde el "nosotros" es americano, es leído como afirmación de la nacionalidad rioplatense, "de la madurez nacional para la emancipación", según afirma el autor a renglón seguido de transcribirlo. Y de igual manera, sin advertirlo, en los párrafos siguientes convierte todas las expresiones del sentimiento de identidad americana de los textos que comenta en manifestaciones del sentimiento nacional de cada futuro país hispanoamericano. Sentimiento que, con respecto a Buenos Aires, considera preexistente desde 1806.

Este tipo de lectura de documentos de los primeiros tiempos de la Independencia, o de fines del período colonial, es uno de los hábitos en que hemos incurrido con más frecuencia. ${ }^{10}$ Así, escritos como la Representación del Cabildo de la ciudad de México de 1771, para tomar el ejemplo de un documento de relevancia, que reclama la exclusividad en la provisión de empleos públicos para los españoles americanos, puede ser leído como expresión de nacionalismo mexicano, cuando en él no se empleá este concepto sino el de americano. ${ }^{11}$

De tal manera, no puede menos que llamarnos la atención, cuando reflexionamos sobre ello, la paradójica confusión en que seguimos incurriendo con sorprendente inadvertencia: que los hombres de la Independencia "hablen" como americanos y que nosotros los "escuchemos" como mexicanos, venezolanos, peruanos, chilenos o argentinos...

De la misma manera, en un análisis rico en hallazgos y sugerencias como el que David Brading dedica al tema del nacionalismo mexicano, ${ }^{12}$ las distintas apelaciones realizadas por los autores que 
estudia, a lo español americano, a lo mexicano, y a lo local o regional, son registradas como distintos grados en la emergencia del sentimiento nacional mexicano, sin atender a su posible calidad de indicadores de una indefinición respecto de la identidad nacional. Criterio que no hace posible discernir si un rasgo computado como nacionalista traduce un real sentimiento o propósito nacional, o sólo una afirmación de la oposición a lo español, o a lo europeo, en cuanto variante localista, en suma, del fuerte sentimiento de americano característico de esos tiempos. ${ }^{13}$ Pues, si bien se mira, en los escritos de la etapa final de la Nueva España y comienzos de la independencia, la apelación a lo mexicano podría ser interpretada como una forma que recoge la fuerte peculiaridad de cultura de los pueblos de la Nueva España, de afirmar esa oposición a lo español. Una forma alternativa, con fuerte sustrato local, del concepto de americano ${ }^{14}$; concepto, claro está que indica al mismo tiempo la existencia en la Nueva España de algo que falta en otras regiones hispanoamericanas; esto es, una mayor intensidad de rasgos culturales diferenciadores que, más tarde, serán apoyos del sentimiento nacional.

Frente a esta visión, resulta más razonable el reparo de Octavio Paz cuando prefiere hablar de singularidad y no de nacionalidad mexicana, a la que no considera aún existente en el siglo XVIII. Según su ponto de vista, la peculiaridad del México colonial se expresa en algo que no es una manifestación de nacionalismo sino una "conciencia de la singularidad mexicana", y cuyo origen es muy temprano, pues aparece inmediatamente de producida la conquista. Esa consciencia

"Se expresó primero en altas creaciones artísticas y especulaciones sacro-históricas; después en alegatos políticos como el célebre sermón de Fray Servando Teresa de Mier en la Basílica de Guadalupe en el que afirmó, ahora ya como uno de los fundamentos del derecho a la independenica, la identidad entre Quetzalcóatl y el Apóstol Santo Tomás”.

Y añade a continuación: 
"Los historiadores han interpretado todo esto como una suerte de prefiguración del nacionalismo mexicano. El mismo Lafaye incurre en esta visión lineal de la historia mexicana. Dentro de esta perspectiva los jesuitas Sigüenza y Góngora y hasta Sor Juana Inés de la Cruz serían los "precursores' de la Independencia mexicana. Convertir a una poetisa barroca en un autor nacionalista no es menos extravagante que haber hecho del último tlatoani azteca, Cuauhtémoc, el origen del México moderno." 15

Y luego de observar que el barroco mexicano tiene rasgos propios, perceptibes en la poesía y en la arquitetura, añade:

"Estamos en presencia no de un nacionalismo artístico - invención romántica del siglo XIX - sino de una variante, ricamente original, de los estilos imperantes en España al finalizar el siglo XVII. "16

\section{Estado y nacionalidad}

En el otro polo del criterio de rastrear las actuales nacionalidades hispanoamericanas a través del proceso de formación de identidades colectivas en el período colonial, el problema ha sido abordado como aspecto de la relación Estado-Nación. Tal como surge de este texto del historiador chileno Mario Góngora:

(En Chile), “...el Estado es la matriz de la nacionalidad: la nación no existiría sin el Estado, que la ha configurado a lo largo de los siglos XIX y XX."

O de este otro, tomado de la misma obra:

"La nacionalidad chilena ha sido formada por un Estado que ha antecedido a ella, a semejanza, en esto, de la Argentina; y a diferencia de México y del Perú, 
donde grandes culturas autoctonas prefiguraron los Virreinatos y las Repúblicas." 17

Este enfoque, que restringe su validez a algunos casos, suponiendo que en otros sí se daba el desarrolo natural, confirma a este último en cuanto se propone como excepción. Es decir, se trata de una perspectiva en la que el supuesto de una relación necesaria entre identidades étnicas y nación no ha sido abandonado. Esto se revela en que, por una parte, Góngora considera que las culturas indígenas prehispánicas conformaron las nacionalidades mexicana o peruana, sin advertir las distancias no sólo entre las culturas prehispánicas y la colonial, sino, por ejemplo, entre las mismas culturas prehispánicas mesoamericanas, como la maya y la azteca; es decir, asignando a la función mítica que el indigenismo ha cumplido en la formación de algunas naciones hispanoamericanas el valor de una comprobación historica. Y, por otra parte, en que esto ocurre por el presupuesto de Góngora de que lo natural es la emergencia de una nacionalidad como efecto de una identidad tejida a lo largo de un largo arco temporal. Esquema en el que las excepciones como la de los casos argentino y chileno se deberían a una débil presencia de ingredientes culturales diferenciadores, circunstancias que requieren entonces la acción supletoria del Estado.

Pero, por otra parte, sucede que la noción de una formación de la nacionalidad por obra del Estado omite la historia viva de las luchas, conflitos y conciliaciones de las distintas partes que confluyeron en las nuevas naciones, desde Argentina y Chile hasta México. Esto es, la necesaria atención que debemos prestar a la formación de la nación, no solo por influjo de elementos míticos, capaces de moldear el imaginário popular, sino también como fruto de acuerdos políticos, tan vivos y recurrentes en todos los nuevos países hispanoamericanos. Realidad que no ha sido ignorada pero sí frecuentemente deformada, al convertírsela en el relato de los vaivenes del proceso de organización nacional, expresión ésta que pone la nación ab initio del proceso, y concibe lo que viene después como una historia, sea de anárquicas resistencias localistas al logro de esa organización, sea de meritoria lucha de caudillos locales en pro de ese objetivo. 
De manera que si afirmásemos que el Estado construye la Nación, sería lícito preguntarnos a qué proceso histórico real estaríamos aludiendo. Pues es evidente que no se trata del Estado en cuanto tal, con su conjunto de normas y órganos políticos y burocráticos de ejecución - niveles que tienen sí que ver con el asunto, pero como momentos posteriores a las tomas de decisiones -, sino a los hombres, individual o grupalmente considerados, que ejercen el poder o que influyen en él. De manera que la expresión el Estado cubre en realidad un ámbito histórico de otra naturaleza: la historia de decisiones políticas relativas al uso de medios estatales para la construcción o modificación de sentimientos, ideas, imaginarios, (o cómo querramos llamarlo), colectivos... Ambito en el que es decisiva la acción de los intelectuales, tales como literatos, historiadores, periodistas, juristas, entre otros, que pueden o no participar en el Estado, pero que cumplen en la construcción de una identidad una función sustancial. Observación con la que queremos también apuntar al hecho de que aún cuando admitamos que la nación ha sido una "construcción", la perspectiva de reducir esa función al Estado no se justifica.

La tesis de una nación producto de un actuar "a proyecto" del Estado ha hecho fortuna, posiblemente por parecer una alternativa al caso inverso, y siempre bajo el supuesto no sometido a crítica, del carácter natural de aquél. Así, la vemos retomada en un Simposio dedicado al tema de Estado y nación en el mundo andino:

“... la nación como expresión consciente de las castas coloniales no creó el Estato, sino que es éste el que surge como fundador de la nación" ${ }^{18}$

Pocos testimonios más elocuentes del estado de equivocidad que rodea la discusión sobre el tema, que el que proporciona el debate de las ponencias de ese simposio. Tanto por la trampa del supuesto ejemplo europeo, ${ }^{19}$ como por la no percepción de los viejos supuestos que impiden siquiera formular con claridad el problema. Parece por ello razonable que la Comisión encarjada de redactar las conclusiones del debate,expresara sólo lo que sigue: 
"Como conclusión a los debates que siguieron a estas ponencias, la comisión cree que le concepto de Estado-nación no permite, por ahora, establecer un acuerdo entre los investigadores, ni delinear la realidad observada. Prefirio entonces hacer el inventario de los puntos de convergencia." 20

\section{Estado nacional, estados provinciales}

Una variante en esta perspectiva es considerar el asunto como una interrelación entre Estado y sociedad civil. Así lo enfoca un trabajo que ha intentado hacer de la historia del Estado argentino algo que responda a lo específico del tema - y no el resumen de procesos y conflictos políticos y sociales que habitualmente la reemplaza. ${ }^{21} \mathrm{El}$ trabajo de Oszlak parece escapar al supuesto de una nación existente en 1810, cuando concibe el processo como de una generación por mutuo influjo de Estado y sociedad civil:

“...el Estado nacional surge en relación a una sociedad civil que tampoco ha adquirido el carácter de sociedad nacional. Este carácter es el resultado de un proceso de mutuas determinaciones entre ambas esferas."

Pese a esto, no deja de ser totalmente inmune al condicionamiento de los supuestos que comentamos, pues luego de definir las condiciones de lo que llama "estatidad" - entre las que coloca la capacidad de internalizar una identidad colectiva -, observa que

"El tema de la estatidad no puede entonces desvincularse del tema del surgimiento de la nación, como otro de los aspectos del proceso de construcción social". ${ }^{22}$

De manera que si bien el autor ha sorteado la tendencia a suponer existente la nación argentina hacia 1810 , no deja de colocarla como 
universo excluyente, aunque bajo la forma de meta del proceso historico. El resultado es que las alternativas a los diversos proyectos de organización estatal rioplatense, como fueron los estados autónomos regionales - provinciales - no son percibidos y sólo quedan aludidos como "situaciones provinciales", o "poderes locales":

"La dominación colonial o el control político de las situaciones provinciales dentro del propio ámbito local, son formas alternativas de articular la vida de una comunidad, pero no representan formas de transición hacia una dominación nacional". ${ }^{23}$

La perspectiva de considerar las tendencias autonomistas de las provincias sólo como "demoras" en la producción de la amalgama social necesaria para el sugimiento del Estado nacional, ha sido una de las alternativas más atractivas para la historiografia latinoamericana. Sin embargo, si persistiésemos en ella, correríamos el riesgo de perder no sólo parte de la historia de los estados emergentes del colapso del dominio ibérico, sino también el sentido de los conflictos interregionales del período, que, en buena medida, estaban condicionados por el hecho de que cada uno de esos estados autónomos provinciales eran otros tantos conatos de construcción de naciones, a veces apenas esbozados, otras con mayores pretensiones, pero finalmente fracasados.

\section{LOS PROBLEMAS DEL VOCABULARIO}

Uno de los factores de mayor peso en este conjunto de confusiones es nuestra inadvertencia del uso cambiante, a lo largo de la historia moderna y contemporánea, de ciertos términos que constituyen otras tantas claves para la interpretación de los orígenes de las naciones latinoamericanas. De alguna manera, se trata de la inadvertencia de hasta que punto seguimos pagando tributo a las concepciones políticos del Romanticismo, bajo cuyo influjo se forjaron estas naciones - y también buena parte de las europeas - , a través del uso romántico de términos como, por ejemplo, nación, nacionalidad, 
patria o pueblo. No nos proponemos proporcionar nuevas definiciones de tales conceptos que, como el caso de nacion, como expondremos más abajo, resulta prácticamente indefinible. Pero sí aclarar que nacionalidad será usado como refiriendo a un grupo humano con algún grado de homogeneidad cultural y conciencia de ella y de su diferencia con otros grupos, mientras que nación referirá a la presencia, políticamente organizada en Estado, de grupos humanos contemporáneos (siglos XIX y XX). Porqué esta limitación? Porque, más allá del debate sobre la utilidad y pertinencia de las definiciones, no hay nada menos definible que el concepto de nación, ni, por consiguiente, nada menos propicio al tratamiento histórico del problema que la discusión sobre su definición.

Observa al respecto Eric Hobsbawm, en un reciente libro dedicado al tema, que la pregunta "qué es una nación," no tiene respuesta satisfactoria. Para lograla, se han hecho intentos de establecer criterios objetivos, como lenguaje, territorio común, historia común u otros, pero todas estas definiciones objetivas han fracasado por la razón obvia que sólo una parte de quienes pertenecen a alguna nación pueden mostrar tal comunidad de rasgos. De manera que como estrategia para el manejo del problema por parte de los historiadores, parecería más provechoso comenzar enfrentándose con las manifestaciones históricas del uso del concepto de nación - por ejemplo, con el nacionalismo -, que con la realidad a la que se supone que ese concepto refiere. ${ }^{24}$

\section{Nación y nacionalidad en el Río de la Plata}

Por otra parte, en el caso rioplatense nuestro criterio es el de prescindir del presupuesto de la mayor parte de la tradición historiográfica que concibe la existencia de una nacionalidad argentina hacia 1810 como basamento del proceso de la Independecia. ${ }^{25}$ Respecto del Uruguai, una perspectiva crítica similar fué sostenida por Carlos Real de Azúa, al censurar lo que llamaba "tesis independentista clásica" de la historiografía uruguaya. Real de Azúa rastrea los orígenes de esa tesis que constituye, afirma, 
“... desde Ramírez, Zorrilla de San Martín y Bauzá hasta Blanco Acevedo y Pivel Devoto línea dominante de nuestra historiografia tradicional." ${ }^{26}$

Según ella, los orientales habrían aspirado a su independencia desde el fin de la dominación hispánica, al punto que en el proceso de disgregación de ese dominio se habria configurado ya una nacionalidad uruguaya.

Retornando al caso de Argentina, creo que si abandonamos entonces este supuesto de un Estado y una nación surgiendo de una nacionalidad preexistente - al menos si "suspendemos el juicio" sobre el particular - podremos interpretar mejor qué es lo que los protagonistas de esta historia consideraban estar haciendo en 1816, 1826 y 1831, al pretender fundar constitucionalmente, fuese las Provincias Unidas del Río de la Plata, las Provincias Unidas en Sud America, o la Confederación Argentina.

Como ha sido ya observado respecto de la historia europea, ${ }^{27}$ el término nación en tiempos de la Revolución Francesa no poseía las connotaciones étnicas que adquirió con el Romanticismo, y que se expresarían en el uso del concepto de nacionalidad. Por ejemplo cuando en 1815 el redactor de La Gaceta de Buenos Aires cree necesario expresar qué entiende por nación escribe lo siguiente:

"Una nación no es más la reunión de muchos Pueblos y Provincias sujetas a un mismo gobierno central, y a unas mismas leyes..."

$\mathrm{Y}$ añade:

"...la verdad de la historia nos dice que los Pueblos conmovidos y armados por el amor de la libertad no aparecen considerables, ni logran protectores, ni triunfan de la tiranía hasta que se constituyen en Naciones por la unión entre sí, y la direccción de una sola autoridad suprema..." ${ }^{28}$ 
Como vemos, para el redactor de La Gaceta..., el concepto de nación era ajeno al de nacionalidad. En esto, no hacia otra cosa que reproducir el criterio predominante en los años que van de las revoluciones norteamericana y francesa a la irrupción del Romanticismo. Por ejemplo, como se observa en este párrafo de Sieyès:

"Qué es una nación? Un cuerpo de asociados que viven bajo una ley común y están representados por la misma legislatura." 29

Sin embargo, el concepto de nación referido a un grupo humano que comparte una cultura que los distingue del resto de los seres humanos, no estaba ausente en la literatura europea del siglo XVIII. Por ejemplo, el caso de los griegos de la Antigüidad que formaron, se señalaba, numerosos estados distintos pero tenían conciencia de su singularidad cultural, era un lugar común de la literatura política de la época, como también ocurría, según comprobaremos enseguida en el caso rioplatense. Asimismo un artículo del Padre Feijóo en su Teatro Crítico Universal, muestra un concepto de nación similar al anterior. ${ }^{30}$ Pero también es cierto que no se establecia entre esta noción de un grupo humano culturalmente distinto y un Estado, la relación necesaria que supondrá el llamado principio de nacionali$d a d$, a partir del comienzo de su difusion en los años treinta del siglo XIX. Y éste es uno de los puntos sustanciales del asunto. Porque si quitamos del medio la afirmación, puramente ideológica, de la existencia de una nacionalidad como base de la aparición de la nación, la comprensión del proceso de génesis de nación y Estado se allana totalmente. Puesto que, sustancialmente la génesis de la nación es la misma que la del Estado.

Es por eso que cuando se afirma que el Estado crea la nación en ciertos casos, se incurre en realidad en una perogrullada, dado que siempre la nación contemporánea ha sido creada por el Estado, en la medida que ella no es la traducción política de una nacionalidad, sino

* Critério según el cual las naciones debían tener presencia internacional como Estadosnaciones independientes y soberanos. Es decir, lo que posteriormente sería llamado simplemente nacionalismo. Véase al respecto las citadas obras de E. Gellner y E. Hobsbawm, lugs. cits. 
el fruto de la emergencia de una nueva legitimidad, sucesora de la de las monarquias patrimoniales, que al fundarse en la soberania popular, y al reglar el ejercicio de esa soberania con las formas del régimen representativo liberal, postula a la nación como sujeto de la imputación de la soberanía. Esa postulación es la partida de nacimiento de la nación que realmente existe en los siglos XIX y XX. Nación que, a partir del Romanticismo, en el momento mismo de nacer, intentará justificar su legitimidad apelando al esquema subyacente al principio de las nacionalidades.

\section{La discusión sobre el tema en la política rioplatense}

La cuestión de si existía o no una nación rioplatense en tiempos de la Independencia no es algo que surja de la actual investigación histórica. Fue un problema que preocupó ya en los primeros tiempos de vida independiente, al punto que en el Congresso Constituyente de 1824-26, donde el asunto fue arduamente discutido, se enfrentaron quienes opinaban que la nación existía desde 1810 y quienes consideraban que aún no tenía existencia. ${ }^{31}$

Más aún. En el curso de uno de esos debates, particularmente agitado, el Presbíterio José Ignacio Gorriti, diputado entonces por la provincia de Salta, se ocupó del asunto en un discurso en el que queremos detenermos por su notable significación. En ese discurso, Gorriti se propuso distiguir las posibles maneras de interpretar el concepto de nación ,como una forma de abordar mejor el problema de la existencia o no existencia de una nación rioplatense. Y al hacerlo, dejó traslucir muy nítidamente qué era lo que estos hombres pensaban estar haciendo en un congreso constituyente.

"De dos modos - argumentaba Gorriti - puede considerarse la nación, o como gentes que tienen un mismo origen y un mismo idioma, aunque de ellas se formen diferentes estados, o como una sociedad ya constituida bajo el régimen de un solo gobierno." 
En la primera parte de la alternativa Gorriti alude al término nación en una modalidad de alguna manera cercana al posterior uso del término nacionalidad. Mientras que en la segunda parte expone la acepción corriente en su época y predominante antes de la difusion del principio de nacionalidad. Es esta segunda acepción, como comprobaremos más abajo, la que emplea Gorriti cuando discute la existencia o no de una nación rioplatense 0 argentina.

Pero previamente analicemos el otro sentido que admite Gorriti, quien, inmediatamente del citado párrafo, usa algunos ejemplos:

"En el primer sentido fue un nación la Grécia, sin embargo de que estaba dividida en una multitud de estados pequeños, que hacian otros tantos gobiernos particulares, con leyes propias del resto de la nación. Es también lo mismo la Italia: toda ella se considera una nación, sin embargo que está subdividida en una multitud de estados diferentes."

$Y$ añade algo que en realidad nos proporciona un indicio más de que si en el Río de la Plata había entonces algún sentimiento posible de nacionalidad, en el sentido con que será entendido este término luego de la difusión del principio de nacionalidades y hasta los días que corren, era un sentimiento hispanoamericano:

"Puede considerarse del mismo modo la América, a lo menos toda la del Sud, como una sola nación, sin embargo de que tiene estados diferentes, que aunque tengan un interés común tienen los suyos particulares, que son bien diferentes: mas no bajo el sentido de una nación, que se rije por una misma ley, que tiene un mismo gobierno."

No cuesta mucho advertir que es este último sentido, por la forma en que el párrafo que lo incluye lo utiliza, el que realmente interesaba en la discusión. Es decir, que la existencia de una identidad cultural-según criterio que, ya lo vimos, era común en la época- no era concebida como determinante del origen de una nación. Para dar 
lugar al establecimiento de una nueva nación debían cumplirse otros requisitos, relativos a decisiones políticas adoptadas por grupos que al margen de la conciencia de compartir con otros seres humanos diversos rasgos - tales como lenguaje, religión, "glorias" históricas, entre otros - concebían la formación de una "nación" como concerniente a otra esfera de decisiones: la de los intereses especificamente políticos, esto es, relativos a la organización de un sistema político representativo, basado en el supuesto de la soberanía popular. De manera tal que la nueva nación no necesariamente debía incorporar a todos los que compartían las mismas características culturales.

Este criterio de época es ya visible en aquel texto de Mariano Moreno, de 1810, en el que se pregunta por los alcances territoriales de la nueva nación a organizar:

"Nos hay pues inconveniente, en que reunidas aquellas provincias, a quienes la antigüidad de íntimas relaciones ha hecho inseparables, traten por sí solas de su constitución. Nada tendría de irregular, que todos los pueblos de América concurriesen a ejecutar de común acuerdo la grande obra, que nuestras provincias meditan para sí mismas; pero esta concurrencia sería efecto de una convención, no un derecho a que precisamente deban sujetarse, y yo creo impolítico y pernicioso, propender a que semejante convención se realizase. $" 32$

Moreno evalúa aquí las posibilidades de constituir un nuevo Estado y descarta como irrealizable la unidad americana, mientras en cambio sugiere basarse en aquellas provincias a las que unían la "antigüedad de íntimas relaciones", con evidente referencia a los vínculos de Buenos Aires y otras provincias rioplatenses.

Retornemos al texto de Gorriti que, inmediatamente al párrafo citado, pasa a analizar qué quiere decir el término nación, y lo hace según la segunda de las acepciones que había expuesto al comienzo de su argumentación. "Yo pregunto, qué cosa es una nación libre?" Y responde: 
"Es una sociedad en la cual los hombres ponen a provecho en común sus personas, propiedades, todo lo que resulta de esto. En [con] sus personas ponen su industria, su fuerza física, su capacidad intelectual, sus virtudes, su sangre, y su misma vida."

$\mathrm{Y}$ a esta definición de lo que concibe como una nación libre es decir, no sometida a una dominación ajena -, agrega las siguientes aclaraciones que nos permiten percibir mejor la distancia que media entre esta perspectiva y la que difundirá el Romanticismo:

"Mas cuando ponen esto a producto en la sociedad lo hacen bajo ciertas condiciones, por las cuales ellos calculan lo que ceden y lo que reciben. Cuando ceden, y ponen a beneficio de la sociedad esta porción de bienes, es porque las condiciones con que ellos las ceden, y condiciones que exigen, son más vantajosas al individuo, que la conservación de sus derechos plenos en el estado de la natureza. Es pues en este sentido que yo he dicho, y repito, que no tenemos nación." 33

Las variaciones históricas del uso de nación en el Diccionario de la Real Academia Española.

No deja de ser útil reparar en que el propio Diccionario de la Real Academia Española registra actualmente varias acepciones del término nación, cuyas dos principales constituyen otras tantas "reliquias" de estos dos usos históricos que estamos analizando:

"Conjunto de los habitantes de un país regido por el mismo gobierno".

"Conjunto de personas de un mismo origen étnico y que generalmente hablan un mismo idioma y tienen una tradición común." ${ }^{34}$ 
La versión original de la primera de esas acepciones data de la primera edición del Diccionario (1726-1739) y se mantuvo en las ediciones de 1780 y 1803 . Su texto no coincidŕa totalmente con el de la versión que hemos citado pues faltaba la mención explícita del gobierno:

\section{"La colección de los habitantes en alguna Provín- cia, país o Reino." 35}

Pero en una y otra forma, ambas nos muestran un concepto de nación como referente a un conjunto de seres humanos reunidos por su pertenencia a un país regido por un mismo gobierno.

Esta definición coincidia, por otra parte, con la del Diccionario de la Academia Francesa. La palabra nación figura en el Diccionaire de esa Academia, edición de 1694, y se reproduce en las ediciones de 1740 y 1762 :

...allí se da una definición que se funda en la unidad de gobierno, de administración y de lengua; una nación está constituida por ' todos los habitantes de un mismo estado, de un mismo país (pays) que viven bajo las mismas leyes y usan el mismo lenguaje." $" 36$

En cambio, la incorporación del concepto de etnicidad en el Diccionario español la encontramos recién en la edición de 1925 y su definición es exactamente como la que hemos citado de la edición de 1984.

Esa modalidad de uso del concepto de nación no deja de generar en un lector contemporáneo una suerte de perplejidad por la ausencia de toda referencia a alguna modalidad étnica o cultural, tal como se registra desde la edición de 1925. O tal como se la incorpora en las acepciones del término que ofrece otro de los más autorizados diccionarios de la lengua española, el de María Moliner:

"Comunidad de personas que viven en un mismo territorio regido todo él por mismo gobierno y unidas por lazos étnicos o de la historia.-Esa comunidad, 
junto con el territorio y todo lo que pertenece a él . Comunidad de personas de la misma raza, con los mismos usos, particularmente el mismo idioma, que, por alguna razón histórica ocupa un territorio dividido entre vários países". ${ }^{37}$

La última de estas acepciones incorpora un criterio distinto, que acentúa la importancia de la perspectiva étnica: el de reconecer una nación por su comunidad étnica y cultural aunque sus integrantes no pertenezcan a un mismo país. Si bien se mira, es tambiém una perspectiva antigua, tal como la habíamos encontrado en el discurso de Gorriti.

La ausencia de un criterio de etnicidad se observa todavia en las varias definiciones de la edición de 1884 del Diccionario de la Real Academia, que pueden considerar-se correspondientes en sustancia con la que predominaba en el Río de la Plata luego de la Independencia. Esas definiciones de la edición de 1884 son las siguientes:

"Estado o cuerpo político que reconece un centro común supremo de gobierno".

"Territorio que comprende, y aun sus individuos, tomados colectivamente"

"Conjunto de los habitadores en una provincia país o reino"

Aqui la novedad - reflejo del proceso político del siglo XIX - es la incorporación, en la primera de estas tres acepciones, de la sinonimia de nación y Estado, entonces, y aún hoy, de uso frecuente,

Por otra parte, el Diccionario, al incluir la etimología de la palabra nación (del latin natio, ônis) nos orienta sobre el origen de otra de las acepciones que registra, bastante curiosa actualmente pero muy usual a mediados del siglo pasado: "extranjero". Se trata de la modalidad quizás más antigua, que remite al uso por los romanos del término natio, quienes lo reservaban para los otros; es decir, se aplicaba a los pueblos no romanos cuyos integrantes compartían un 
mismo y distinto gobierno y unas mismas y distintas costumbres. Este uso figuraba explícitamente en las primeras ediciones del Diccionario. En la de 1726-39:

"Se usa frecuentemente para significar qualquer Extranjero. Es del estilo bajo".

Lo mismo, con ligera variación, incluyen las ediciones de 1780 y 1803 , mientras que esta acepción ya no aparece en la de 1884 .

Otra modalidad, que fué también frecuente en el Río de la Plata durante el siglo pasado, es el uso de nación para refletir al grupo en el que se ha nacido. Ella aparece en la edición de 1803, y se mantiene con las mismas palabras hasta la edicion de 1970.

"De nación. mod. adv. con que se da a entender la natureleza de alguno, o de donde es natural."

Esta modalidad puede ser el fundamento de otro de los sentidos con que se usó el vocablo en el siglo pasado en la América hispana cuando, por ejemplo, se distinguía a los esclavos africanos por "naciones", o se aludía a la "nación" india. Tal como surge de este texto de 1811 que a nosotros puede resultarnos curioso por la yuxtaposición de dos distintas acepciones de la palabra nación:

"En el lenguage de nuestra jurisprudencia el indio es ciudadano, y se halla bajo la protección de las leyes. Estas consideraciones tan justas han movido a la Junta para creer que en aquel tiempo mismo en que se halla rasgado el velo con que la intriga, la mentira, y el egoísmo cubrían la verdad, y en que un gobierno paternal hace consistir toda su gloria en hallarse purgado de la levadura de las pasiones, no podia sin faltar a sus más esenciales deberes excluir del congreso nacional los diputados de la nación indiana..." (subrayado nuestro $)^{38}$ 
Añadamos finalmente, que si nos hemos detenido en estas reflexiones motivadas por los textos del debate de 1826 , es porque ellos nos permiten entender con mayor propiedad los presupuestos del nacimiento de lo que se llamó Provincias del Río de la Plata, Confederación Argentina o Nación Argentina ${ }^{39}$ Así, si quisiéramos discernir en la posición de Gorriti los elementos sustanciales de este criterio de época, tanto para poder distinguirlo mejor del que se difundirá poco después según el principio de nacionalidad, como para permitirnos comprender las características que asumia entonces el debate sobre la organización de una nación rioplatense, podríamos observar lo siguiente:

1. Un reconocimiento de la existencia de una identidad cultural hispanoamericana, que justificaría el concepto de una nación hispanoamericana.

2. Una distinción de otro concepto de nación, como referido a gente que comparte un sistema legal y una forma de gobierno.

3. El criterio que constituir una nación refiere a lo segundo.

4. La inexistencia del supuesto que lo expresado en el punto 1 reclama necesariamente una expresión estatal independiente.

Posteriormente, la actitud ante el problema seguirá el cauce proporcionado por la radical mutación que incorporó el Romanticismo en cuanto respecta a la valoración del pasado y de las tradiciones en suma, de la Historia -, en la conformación del presente, y su peculiar acuñación de los significados de palabras como pueblo y nación. Se pondrán así los fundamentos del llamado principio de nacionalidad cuya general difusión constituirá el supuesto universal de existencia de las naciones contemporáneas hasta los días que corren. Principio según el cual a todo grupo humano culturalmente homogeneo, a toda nacionalidad, debia corresponder una presencia política estatal en la arena internacional. Desde entonces y hasta ahora, ha sido éste el criterio predominante, pese a que la obra de los historiadores abocados al tema ofrezca como resultado la convicción de su no 
pertinencia como explicación de lo realmente ocurrido en la historia contemporánea y sí, en cambio, de su calidad de visión ideologizada del problema.Y consiguientemente, será también el criterio predominante entre los historiadores latinoamericanistas.

Mas allá de la discusión sobre la validez actual del principio de las nacionalidades, lo cierto es que el uso del término nación en tiempos de la Independenica y en los años que corren hasta el Pacto Federal de 1831 respondia al primero de esos criterios puntualizados más arriba. Y es ésta una de las comprobaciones esenciales para poder entender la conformación de la llamada cuestión nacional en ese período.

Nos parece claro así que los que afrontaban ese debate eran representantes de diversos grupos humanos, que participan de un universo cultural hispanoamericano, con fuerte conciencia de ello, pero que poseían por efecto de diversas circunstancias una vida social independiente, expresada en Estados que, aunque llamados provincias, eran también independientes y soberanos. Y es esta circunstancia, la de la existencia en la primera mitad del siglo, de diversos Estados libres, autónomos y soberanos que negociaban la constituición de una nación rioplatense - una nación en el sentido de darse un mismo conjunto de leyes y un gobierno común -, la que la tradición historiográfica elaborada a partir de la segunda mitad del siglo olvidará, obesionada por dibujar los orígenes de la nación argentina em términos de lo que, a partir del romanticismo, se entendería por Estado-nación: la inserción politicamente organizada en la arena internacional de una nacionalidad preexistente.

\section{NOTAS}

1. HOBSBAWM, Eric. La era del capitalismo, Barcelona: Guadarrama, 1977, v. 1, p. 125. "La fabricación de naciones". Nótese lo siguiente:

Seguro que el inglés sabía lo que era ser inglés, y que el francés, el alemán, el italiano o el ruso no tenfan dudas de su identidad 
colectiva? Quizá no, pero en la época de la fabricación de naciones se creía que esto implicaba la lógica, necesaria y deseable transformación de las "naciones" en naciones-estados soberanos, con un territorio coherente definido por el área que ocupaban los miembros de una 'nación' común, su composición étnica y, de modo creciente, su lenguaje. Sin embargo, no hay nada lógico en esta implicación. Si es innegable como la historia la existencia de grupos diferentes de hombres que se distinguen de otros grupos por una diversidad de criterios, no lo es, en cambio, que impliquen lo que el siglo XIX consideraba como tener "categoria de nación"."

2. Por ejemplo, en el caso de Argentina, Bartolomé Mitre, Historia de Belgrano y de la Independencia argentina, 4a. ed., Buenos Aires 1887: véase, entre otros lugares, el comienzo de la Introducción o la p. 302; Vicente Fidel López, Historia de la República Argentina, su origen, su revolución y su desarrollo politico, Buenos Aires: 1913, Prefacio, p. XIII.

3. Lo primero es lo que puede llevar a la fuerte conciencia de la mexicanidad que A. Pagden advierte ya el siglo XVII, pero que no es incompatible con la pertenencia a la nación española. Anthony Pagden, "Identity Formation in Spanish America", en N. Canny and A. Pagden (eds.), Colonial Identity in the Atlantic World, Princeton: University Press, 1987. Este trabajo, si bien es una valiosa síntesis y descripción de los rasgos que van conformando lo que el autor estima una identidad mexicana, como es usual en la historiografia latinoamericanista confunde diversos signos y niveles de diferenciación regional con identidad nacional, al punto de concluir que ya en el siglo XVII los mexicanos habran adquirido no solo una independencia económica y militar, sino también cultural:

"By the middle of the seventeenth century this nation [criolla] had established its own cultural and, insofar as it was permitted to express it, political identity. It had also acquired an independent, diverse, and flourishing economy." (p. 91) 
4. CHIARAMONTE, José Carlos, "Formas de identidad política en el Río de la Plata luego de 1810", Boletín del Instituto de Historia Argentina y Americana "Dr. Emilio Ravignani" 3a . serie, No. 1, Buenos Aires: 1989, p. 71.

5. Supuesto que nos parece similar al observado por Charles Tilly, cuando advierte la tendencia a "la introducción de modelos implícitos de una mal interpretada experiencia occidental como criterios de desarrollo político": Charles Tilly, "Reflexions on the History of European State-making", en Charles Tilly,ed., The Formation of National States in Western Europe, Princeton University Press, 1975, p. 4.

6. RUPP, Peter, "Anthropologie et historie de 1" "identité nationa-

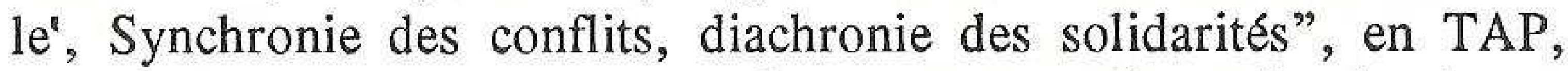
Pierre, Identités collectives et changements sociaux. Production et affirmation de $1^{\bullet}$ identité, [París?]: Privat, 1980. p. 62. El autor, cuyo trabajo es parte de un coloquio internacional dedicado al fenómeno da las identidades colectivas, señala que también la antropología, en cuando se ocupa de las identidades étnicas, reencuentra un pasado histórico o mítico que puede ser proyectado en un devenir común, posible o utópico, que asuma la forma de nación. Rechaza explícitamente el punto de vista de Furet y otros historiadores que hacen de la nación algo que aparece en el momento que todos los ciudadanos son considerados como participantes en la elaboración de la voluntad general. Sobre todo, porque tal consideración privaría al antropólogo y al historiador del instrumento conceptual que les permite asir "...este fenómeno sui generis que trasciende las épocas que es el hecho nacional...", pues... "La nación, como dinámica y como lenguaje, se encuentra en todos los períodos de la historia". Id., p. 63.

7. Un punto de vista distinto, más interesante para los historiadores, es aquél que atiende a la "invención" de las tradiciones que contribuyen a formar la conciencia de una identidad. Véase al respecto Eric Hobsbawm, "Introduction: Inventing Traditions", en Eric Hobsbawm and Terence Ranger, [eds.], The invention of tradition, Cambridge: 
Werner Sollors, ed., The invention of ethnicity, New York: Oxford University Press, 1989, cit. por Kathleen Neils Conzen, Ewa Morawska, George E. Pozzeta, Rudolph J. Vecoli, "The invention of ethnicity: A perspective from the USA", Altreitalie, número 3, anno III, aprile 1990.

"With Werner Sollors, we view ethnicity neither as primordial (ancient, unchangig, inherent in a group's blood, soul or misty past), nor as purely instrumental (calculated and manipulated primarily for political ends). Rather ethnicity itself is to be understood as cultural construction accomplished over historical time." - p. 38. Y: "Since in this conception ethnicity is not a biological or cultural "given", it is restored to the province of history." - p. 54.

8. BARRACLOUGH, Geoffrey, "Historia", en Maurice Freedman, Sigfried J. de Laet, Geoffrey Barraclough, Corrientes de la investigación en las ciencias sociales, 2, Antropología, Arqueología, Historia, Madrid: Tecnos/Unesco, 1981, p. 486.

9. RUIZ GUIÑAZU, Enrique, Epifanía de la libertad, Buenos Aires: Nova, 1952, p. 77 y 79. Rivadavia a Pueyrredón, París, 22 de marzo de 1817, en Bernardino Rivadavia, Páginas de un estadista, Buenos Aires: Elevación, 1945, p. 72. Es de notar que mientras los textos de Rivadavia de estos años, como esa carta de 1817, continúen expresando una identidad de amplitud americana, más tarde, durante el congresso constituyente de 1824-26, sus expresiones serán ya de caracter argentino.

10. Debo confesar que el uso de la primera persona del plural no es meramente convencional. El rasgo criticado es visible también en uno de mis primeros trabajos, Ensayos sobre la "Ilustracion" argentina, Paraná: Facultad de Ciencias de la Educación, 1961, en el que ya el mismo título atribuye a expresiones de la Ilustración hispanocolonial la cualidad nacional argentina. 
11. "Representación que hizo la ciudad de México al rey $\mathbb{D}$. Carlos III en 1771 sobre que los criollos deben ser preferidos a los europeos en la distribución de empleos y beneficios de estos reinos", en J. E. Hernández y Dávalos, Colección de Documentos para la Historia de la Guerra de Independencia de México de 1808 a 1821, México, 1877, Tomo I, p. 427 y sigts. Véase la interpretación de uno de los mejores historiadores latinoamericanistas: John Lynch, Las revoluciones hispanoamericanas, 1808-1826, Barcelona: Ariel, [1976], p. 35. En realidad, el cabildo reclamaba la exclusividad para los americanos, abogando em favor de los derechos de los naturales de cada división administrativa o eclesiática a ocupar los cargos de ellas. Pero los defiende como espanoles americanos, no como mexicanos, vocablo que no aparece en momento alguno (aunque sí el de México), y apoyándose en el derecho español, que obliga a preferir en cada ciudad, provincia o reino, a los nacidos en ella. Así invoca las Leyes 4a. y 5a. tit. 3, Lib. 1 de la Recopilación de Castilla. "Representación...", ob. cit., p. 429.

12. BRADING, David, Los orígenes del nacionalismo mexicano México: Era, 1980.

13. Véase especialmente al respecto el segundo capítulo dedicado a Fray Servando Teresa de Mier.

14. Observaciones que pueden apoyarse, por ejemplo, en que americano, español americano y mexicano sean vocablos intercambiables aún en alguien como Fray Servando Teresa de Mier: véase Fray Servando Teresa de Mier, Cartas de un americano, 1811-12, [reproducción facsimilar], México: PRI, 1976.

15. PAZ, Octavio, "Prefacio", en Jacques Lafaye, Quetzacóaltl y Guadalupe. La formación de la conciencia nacional en México, México: F. C. E., 1977, p. 15. Este enfoque ha sido adoptado como punto de partida por un reciente trabajo consagrado al mexicanismo de los jesuitas novohispanos.

“... me parece más adecuado hablar de " conciencia de singularidad novohispana" y no de "con- 
ciencia de nacionalidad ambos términos usados por otros escritores dedicados a estudiar este fenómeno; ya que México, en aquel tiempo [ siglos XVI a XVIII], no era una nación, sino una colonia española, y el concepto de mexicanidad propiamente dicho no existia aún." Silvia Vargas Alquicira, La singularidad novohispana en los jesuitas del siglo XVIII, México: Universidad Nacional Autónoma de México, 1989, p. 15.

16. Id., p. 16. Octavio Paz percibe adecuadamente el sentido de época del vocablo patria:

"En el siglo XVII los criollos descubren que tienen una patria. Esta palabra aparece tanto en los escritos de Sor Juana como en los de Sigüenza y en ambos designa invariablemente a la Nueva España. El patriotismo de los criollos no contradecía su fidelidad al Imperio y a la Iglesia: eran dos ordenes de lealtades diferentes. Aunque los criollos del seiscentos sienten un intenso antiespañolismo, no hay en ellos, en el sentido moderno, nacionalismo. Son buenos vasallos del Rey y, sin contradicción, patriotas del Anáhuac."

Asimismo

"La universalidad del imperio amparaba la pluralidad de hablas y de pueblos. El patriotismo novohispano y el reconocimento de sus singularidades estéticas no estaba en contradicción con este universalismo." - Id., p. 19

17. GÓNGORA, Mario, Ensayo historico sobre la noción de estado en Chile en los siglos XIX y XX. Sgo. de Chile: Ed. Universitaria, 1986, p. 25 y 37. Góngora enuncia más adelante los rasgos de esa formación de la nacionalidad chilena: 
"A partir de las guerras de la Independencia, y luego de las sucesivas guerras victoriosas del siglo XIX, se ha ido constituyendo un sentimiento y una conciencia propiamente 'nacionales', la "chilenidad'. Evidentemente que, junto a los acontecimientos bélicos, la nacionalidad se ha ido formando por otros medios puestos por el Estado: los símbolos patrióticos (banderas, Canción Nacional, fiestas nacionales, etc.), la unidad administrativa, la educación de la juventud, todas las instituciones. Pero son las guerras defensivas $\mathrm{u}$ ofensivas las que a mi juicio han constituido el motor principal." (p. 38)

Estas tesis de Góngora ha sido motivo de polémica: véanse en la misma edición los trabajos del Anexo 3. "La polémica en torno al Ensayo histórico de Mario Góngora"

18. TOVAR PINZÓN, Hermes, "Problemas de la transición del Estado colonial al Estado nacional (1810-1850)", en J.P. Deler/Y. Saint Geours, (comps.), Estados y naciones en los Andes. Hacia una historia comparativa: Bolivia - Colombia - Ecuador - Perú, dos vols., Lima: IEP/IFEA, 1986, vol. II, p. 371/372.

19. Así, resulta atinada la objeción de Thierry Saignes, apoyada en datos de investigaciones recientes sobre Francia que muestran que hasta fines del siglo XIX no había homogeneidad cultural en el pais, que según la reciente tesis de un historiador norteamericano en la campiña francesa del siglo XIX los campesinos hablaban su dialecto, y que sólo el $5 \%$ de la población manejaba el idioma, y que el resto de la población tampoco cabía en su esquema de homogeneidad cultural - Ob. cit., p. 432. La objeción iba dirigida a Rafael Quinteros quien habia afirmado su visión de una realidad cultural ecuatoriana fragmentada, como peculiaridad frente a la experiencia europea. En Ecuador, sostiene Quinteros, las clases dominantes no cultivaron ninguna solidariedad con los grupos dominados, generándose una cultura "cosida" por la cultura conquistadora, que configuró "una sociedad compleja, sin identidad propia", que no fué el producto 
de alguna acumulación histórica de experiencias comunes al mosaico de hombres y culturas existentes. Mientras en Europa, la clase dominante, fuera terrateniente o burguesa, era una clase nacional,

"portadora de una comunidad cultural unificadora del conjunto de clases, capas y sectores sociales" Id., p. 406 y 404.

20. Idem, p. 666. Véase el entrecruzamiento de tres diversos supuestos contradictorios en este texto de una de las comentadas ponencias:

"El dejar de ser colonia le planteó al Ecuador una tarea en la cual aún trabaja su historia presente y cuyo incumplimiento en siglo XIX se expresó en prolongado desgarraimiento: la constitución o formación de la nación. Algo viviente y cambiante, cosa 'no congelada', la nación ecuatoriana de principios de siglo pasado era una estructura no aprehensible aún. Tres siglos de colonialismo y de Estado Colonial e Ibérico en su contra la habían rezagado en su desarrollo, y la habían hecho soportar múltiples transformaciones y modificaciones". p. 401.

De manera que: 1. la nación ecuatoriana no existía cuando de la independencia, pues había que formarla; 2. Pero esta misión se le planteaba a un sujeto que, por lo tanto, resulta inexplicable: "el Ecuador"; 3. en el segundo párrafo, ya la nación es y al mismo tiempo no es: no era aprensible aún, pero sí algo viviente y cambiante; 4. por último, ahora la nación sí existía desde tiempos coloniales, y sólo se había rezagado.

21. OSZLAK, Oscar, La formación del estado argentino, Buenos Aires: Editorial de Belgrano, 1985.

22. Id., p. 15. 
23. Id., p. 15. Razón tiene en esto Rafael Quinteros en el trabajo ya citado cuando critica a quienes niegan la existencia de Estados en el siglo pasado, global o parcialmente, porque consideran la situación como de una suerte de dominio circence de caudillos militares, o un período de anarquia, o de "aparecimiento tardío de poderes públicos". Sostiene que todo eso suponía una constelación de poderes estatales, que ese "poder real particular" de los caudillos es un fenómeno estatal, junto al que existia toda una superestructura política bien establecida, a veces de origen colonial "Y que configuraba en el siglo XIX una constelación de poderes estatales," - p. 399.

24. Asimismo, se ha definido la nacion - añade Hobsbawm - a partir de criterios subjetivos. Esto es, a partir de la existencia de una conciencia de pertenecer a ella, conciencia que puede ser colectiva Renán: la nación como un plebiscito diario -0 individual. Sin embargo, aduce Hobsbawm,

“... definir una nación por la conciencia de sus miembros de pertenecer a ella es tautológica y sólo provee una guía a posteriori sobre qué es una nación." Eric Hobsbawm, Nations and nationalism since 1780. Programme, mith, reality, Cambridge: University Press, 1990, p. 7.

Respecto de esta cuestión de conceptos, así como del principio de las nacionalidades, al que nos referiremos más de una vez, véase Ernest Gellner, Naciones y nacionalismo, Madrid: Alianza, 1988, p. 13 y sigts.; E. Hobsbawm. ob. cit., p. 14 y sigts.

25. Véase nuestro trabajo "Formas de identidad política...", ob. cit.

26. REAL DE AZÚA, Carlos, Los ortgenes de la nacionalidad uruguaya, Montevideo: Arca, [1990], p. 53 y 62 La cita, en p. 53.

27. El primer sentido de "nación", - observa Hobsbawm - y uno de los más frecuentes en la literatura, fue político. Equiparaba las nociones de "pueblo" y Estado, a la manera de las revoluciones 
norteamericana y francesa. Algo que es familiar en frases tales como "the nation-state", "the United Nations", o la retorica de los presidentes de los últimos tiempos. Pues en los primeros tiempos, añade, el discurso político en los E.E. U.U. prefería hablar de "el pueblo", "la unión", la "confederación", "nuestro territorio común", "el público", el "bienestar público" o la comunidad, de manera de evitar las implicaciones centralizantes y unitarias del término nación, adversas a los derechos de los estados federados. La nación así entendida era, o devino prontamente, aquella que, en el lenguaje francés era, "una e indivisible". Esto es, el cuerpo de ciudadanos cuya soberanía colectiva los constituía en un Estado que era su expresión política. $\mathbb{E}$. Hobsbawm, Nations..., ob. cit., p. 18.

28. La Gaceta de Buenos Aires, 13/V/815, Reimpresión facsimilar..., p. 261.

29. SIEYÈS, Emmanuel J., Qué es el tercer Estado?, Seguido del Ensayo sobre los privilegios, México: U.N.A.M.. 1983. p. 61.

30. FEIJÓO Y MONTENEGRO, Padre Fray Benito Jerónimo, "Amor de la patria y pasión nacional", Obras escogidas, Biblioteca de Autores Españoles, [t. I.], Madrid: M. Rivadeneyra, 1863, p. 141 y sigts.

31. ACTAS del Congreso Nacional de 1824, Sesión del 4 de mayo de 1825, en Emilio Ravignani [comp.], Asambleas Constituyentes Argentinas, Tomo Primero, 1813-1833, Instituto de Investigaciones Históricas de la Facultad de Filosofia y Letras, Buenos Aires, 1937. Los textos que comentamos a continuación pertenecen al debate sobre el proyecto de creación de un ejército nacional. Este proyecto era resistido por representantes de provincias del Interior que veían en ese ejército un posible instrumento del gobierno central para imponerse a los gobiernos provinciales. El argumento más fuerte para impedir la creación del ejército pareció ser, a diputados como Gorriti, la improcedencia de crearlo antes de existir la nación. El argumento de sus opositores era que la nación ya existía desde el año 10 o 16. Curiosamente, muchos diputados de una u otra posición habran 
adoptado el criterio opuesto, uno año antes, al discutirse la posesion de las rentas de la Aduana de Buenos Aires. Diputados de provincias del Interior opinaban que la nación existía, y que por lo tanto esas rentas debían ser nacionales, mientras diputados porteños afirmaban la no existencia de la nación para defender la permanencia de esas rentas en el Tesoro de Buenos Aires. La incongruencia de unos y otros se expresó en la explosión de indignación de uno de los constituyentes, José Valentín Gomez, con posterioridad a la citada exposición de Gorriti:

"Se ha tratado muchas veces da la creación del tesoro nacional. Si: se ha reclamado (no pueden negarlo los diputados que afectan desagradarse u oyen de mala voluntad mis opiniones en este acto), la creación del tesoro nacional. Se ha dicho que existía la nación y que desde que existía ésta, debía existir el tesoro nacional; y hoy cuando se trata de un ejército nacional para defender nuestras provincias hermanas, y nuestra seguridad, se dice que no puede ser. Es posible que cuando se trató del tesoro existia la nación, y cuando se trata del ejército ya no exista? Es posible que para el tesoro podía proveerse, sin esperar a la constitución, y al ejército no se pueda? Señores: esto desespera; $y$ a la verdad que no sé en qué sentido ocupamos este lugar”. Idem, p. 1330.

32. MORENO, Mariano, "Sobre el Congreso convocado, y Constitución del Estado", Escritos. Segunda Edición, Buenos Aires: Estrada, s.f., II, p. 248.

33. Y aclara:

"Para sacudir el yugo peninsular de hecho nos unimos; mas esta unión no forma nación. Por muchos actos positivos hemos manifestado el deseo que tenemos de organizarnos en una nación, pero se ha organizado esta nación, señores? Se reunió una 
asamblea el año 13 y se disolvió el año siguiente sin haber conseguido el objeto. Se reunió un congreso el año 16 , y se disolvió el año $20 .$. " Id. lug. cit.

34. REAL Academia Española, Diccionario de la lengua espanola, vigésima edición, Madrid: 1984, Tomo III.

35. Esta y las demás referencias que siguen a las ediciones del Diccionario de la Real Academia Española, excepto las de la edición de 1984, las tomamos de Lluís Garcia y Sevilla, "Llengua", "nacio" i "estat" al Diccionari de la Reial Academia Espanyola", L'Avens, $\mathrm{n}^{\circ} 16$, mayo de 1979 , p. 50 y sigts. El trabajo se propone, desde una perspectiva motivada por el nacionalismo catalán, mostrar a través de las sucesivas ediciones del Diccionario el propósito de la obra de servir a los intereses del Estado español en el sentido de buscar el sometimiento de los pueblos no castellanos, perspectiva que omite la posibilidad de considerar la inclusión de ciertas acepciones como simple registro de usos de época. Para nuestro propósito, nos proporciona una transcripción comentada de los textos tomados de varias ediciones del Diccionario, desde la primera de 1726 en adelante, pero sin haber podido consultar las ediciones comprendidas entre la octava y la onceava. Para el análises del término Nación usa las ediciones de 1726 (publicada en realidad en seis volúmenes entre ese año y 1739), 1780, 1803, 1884, 1899, y 1925.

36. SOBOUL, Albert, Comprender la Revolución Francesa. Barcelona: Crítica, 1983, p. 282. La idea de nación, comenta Soboul, aún no se diferencia de la de Estado.

37. MOLINER, María, Diccionario de uso del español, Madrid: Gredos, 1986, Tomo II.

38. La Gaceta de Buenos Aires, 24 de enero de 1811, p. 58.

39. Variantes todas que son convalidadas por las reformas de 1860 a la Constitución de 1853, aún vigente, en su art. 35 . 